This electronic prepublication version may contain typographical errors and may be missing artwork such as charts, photographs, etc. Pagination in later versions may differ from this copy; citation references to this material may be incorrect when this prepublication edition is replaced at a later date with the finalized version.

HOSPITAL INFORMATION SERVICES

\author{
Cheryl R. Dee, Linda Garr Markwell, Jane Bridges, \\ and Margaret Bandy, Column Editors
}

\title{
Librarians in the Woods Hole Biomedical Informatics Course
}

\author{
Jane Bridges \\ Christian J. Miller \\ Daniel G. Kipnis
}

\begin{abstract}
What has come to be known as the "Woods Hole course," Biomedical Informatics, is a week-long course sponsored by the National Library of Medicine which has been offered since 1992. Its partic-

Jane Bridges, ML, AHIP (BridgJa1@memorialhealth.com) is Clinical Campus Librarian for Mercer University at the Health Sciences Library, Memorial Health University Medical Center, 4700 Waters Avenue, Savannah, GA 31403. Christian J. Miller, MLS (cjmiller@ncifcrf.gov) is Public Services Librarian, Scientific Library, National Cancer Institute at Frederick, Wilson Information Services Corporation, Building 549, P.O. Box B, Frederick, MD 21702-1201. Daniel G. Kipnis, MSI (dan.kipnis@ jefferson.edu) is Education Services Librarian, Academic and Instructional Support and Resources, Thomas Jefferson University, 1020 Walnut Street, Room 410, Philadelphia,

Comments and suggestions should be sent to the Column Editors: Cheryl R. Dee (cede@chuma1.cas.usf.edu), Linda Garr Markwell (liblgm@emory.edu), Jane Bridges (BridgJa1@memorialhealth.com), and Margaret Bandy (bandym@exempla.org).
\end{abstract} PA 19107.

Medical Reference Services Quarterly, Vol. 25(1) 2006

Available online at http://www.haworthpress.com/web/MRSQ

(C) 2006 by The Haworth Press, Inc. All rights reserved.

doi:10.1300/J115v25n01_07 
ipants include librarians, clinicians, educators, and administrators. This article discusses the content of the course and its applicability to medical librarians. [Article copies available for a fee from The Haworth Document Delivery Service: 1-800-HAWORTH. E-mail address: <docdelivery@haworthpress. com> Website: <http://www.HaworthPress.com> () 2006 by The Haworth Press, Inc. All rights reserved.]

KEYWORDS. Informatics, biomedical informatics, medical informatics, cooperative behavior, information systems, Integrated Advanced Information Management Systems, IAIMS

\section{INTRODUCTION}

Since its inception in 1992, the reputation and prestige of the "Woods Hole" course for Biomedical Informatics has been increasing among medical librarians. Informally and increasingly, the name is heard at national, regional, and state library meetings, as well as those of other professions. A formal evaluation of the course has been published. ${ }^{1}$ At this writing, approximately 600 librarians, clinicians, administrators, and educators have attended the course, with that number increasing by a present rate of 60 fellows per year.

The course brings together elements of database design; human-computer interfaces; medical vocabularies, and coding systems; medical decision analysis methods; evaluation methods in medical informatics; technical exercises, knowledge-based databases; telemedicine; consumer informatics; education informatics; and strategies for designing and managing clinical information systems. The year 2005 marked the fourteenth year the course has been offered, and the twentieth class. This paper is an attempt to summarize the week-long spring course and comment on the role of the librarian in the field of informatics. Each participant's experience will differ, and, as the course is dynamic, it will differ from spring to fall and from year to year.

The program is held in the spring and again in the fall. It is sponsored and fully funded by the National Library of Medicine (NLM) and is designed as a survey course of Biomedical Informatics taught by an all-star team of experts. Applications are taken from potential course participants once per year, and students are accepted into the spring or fall session. The course is held on Cape Cod at the facilities of the Marine Biological Laboratory (MBL) in Woods Hole, Massachusetts, the oldest private marine laboratory in the western hemisphere dating to 1888. Participants are provided with dormitory-style accommodations and receive three meals a day at the facility's cafeteria. Woods 
Hole is a village, and participants stroll a couple of blocks from the dormitory to the facility where classes are held, which is located on the water.

\section{OVERVIEW}

During the week of May 30, 2005, 30 informatics students attended the spring session of the Biomedical Informatics course as fellows. The 30 fellows from the spring session included: 14 health science librarians/administrators; eight physicians; an administrator; two information system professionals; three nurses; a veterinarian; and an educator. There were 45 advanced degrees held among the 30 participants. The fellows came from diverse occupational settings: 20 university, seven community, two member organizations, and one government. Eighteen states were represented along with one foreign country, Canada. During the spring session, instructors represented Duke, Harvard, the National Library of Medicine, the Marine Biological Laboratory, Vanderbilt, and Columbia, to name just a few.

Along with the 23 lectures totaling over 40 hours, the program included hands-on sessions on Web page design, developing Web-based interfaces for databases, and decision trees. Participants followed the course presentations on wireless laptop computers and took notes in PowerPoint Notes view.

One indication of the emphasis that the National Library of Medicine puts on the importance of the course is the involvement of several NLM staff and its director, Donald A. B. Lindberg, M.D. Dr. Lindberg attended the opening reception, conducted the second session of the course entitled, "Current Issues in Medical Informatics," and was present in the classroom for many of the presentations during the entire week, including the final student project presentations. He was present and accessible at meals in the cafeteria as well as at other social events, and morning and afternoon breaks. This, along with a casual dress code, contributed greatly to the atmosphere of collegiality and learning generated by all the instructors. The hospital librarian was a full participant, along with the clinicians, educators, administrators, and instructors, who represented some of the best minds in the country in the field of biomedical informatics.

\section{PROGRAM}

The first formal session was entitled, "What is BioMedical Informatics?" and was conducted as an hour-long discussion. A 1990 article in JAMA defined the term thusly: "Medical informatics is the field that concerns itself with the cognitive, information processing, and communication tasks of medi- 
cal practice, education, and research, including the information science and the technology to support these tasks." It soon became clear during the discussion that the field of biomedical informatics has broadened as computer technology has become widely used in so many patient care applications. To a hospital librarian who was unsure whether her milieu extended into this area, it became apparent that knowledge-based information has become more and more firmly integrated into the whole of patient care as a result of the march of technology. As King and MacDonald concluded recently, "Medical informatics training is a wonderful opportunity for librarians to collaborate with professionals from the sciences and other information disciplines. Librarians' unique combination of human research and technology skills provides a valuable contribution to any program." 3 This became apparent during the week, as the program offerings touched a variety of areas in which different participants possessed different strengths.

The session, "Principles of Controlled Terminology," was a good example of a topic that enhanced a medical librarian's experience and made communication with clinicians more understandable. The threads of the discussion involved a clinical case and the use and reuse of data; coding clinical data; available terminologies; terminology concepts and desiderata; and practical considerations. The basic premise was easily understood by a librarian, who works with terminology and hierarchical structure in information retrieval. This understanding was enhanced as a result of the discussion of clinical coding, which illustrated the reasoning behind other hierarchies of information terminology. With that knowledge in hand, the hospital librarian got a behind-the-scenes look at other hospital operations, the challenges involved, and the similarities and differences in various systems.

Another session that enhanced the experience of the hospital librarian was, "Decision-Analytic Methods for Evidence-Based Practice." It described the informatics foundation for evidence-based practice; identified the components of expected value decision making; and demonstrated a decision tree using a decision analysis software package. With the current emphasis on evidence-based medicine, it was informative for a hospital librarian to see a decision tree at work, and to infer what the provision of knowledge-based information would contribute to that process.

This year, the first Biomedical Informatics Blog was introduced at the suggestion of one of the fellows (see Figure 1). It was implemented during the course week and was available for fellows to converse during and after the course.

Every one of the lectures provided information and insight into growing topics involved in medical informatics. Because the class consisted of a large percentage of librarians, many discussions related to how each of the topics 
FIGURE 1. Course Blog <http://courses.mbl.edu/mi/mi_blog/>

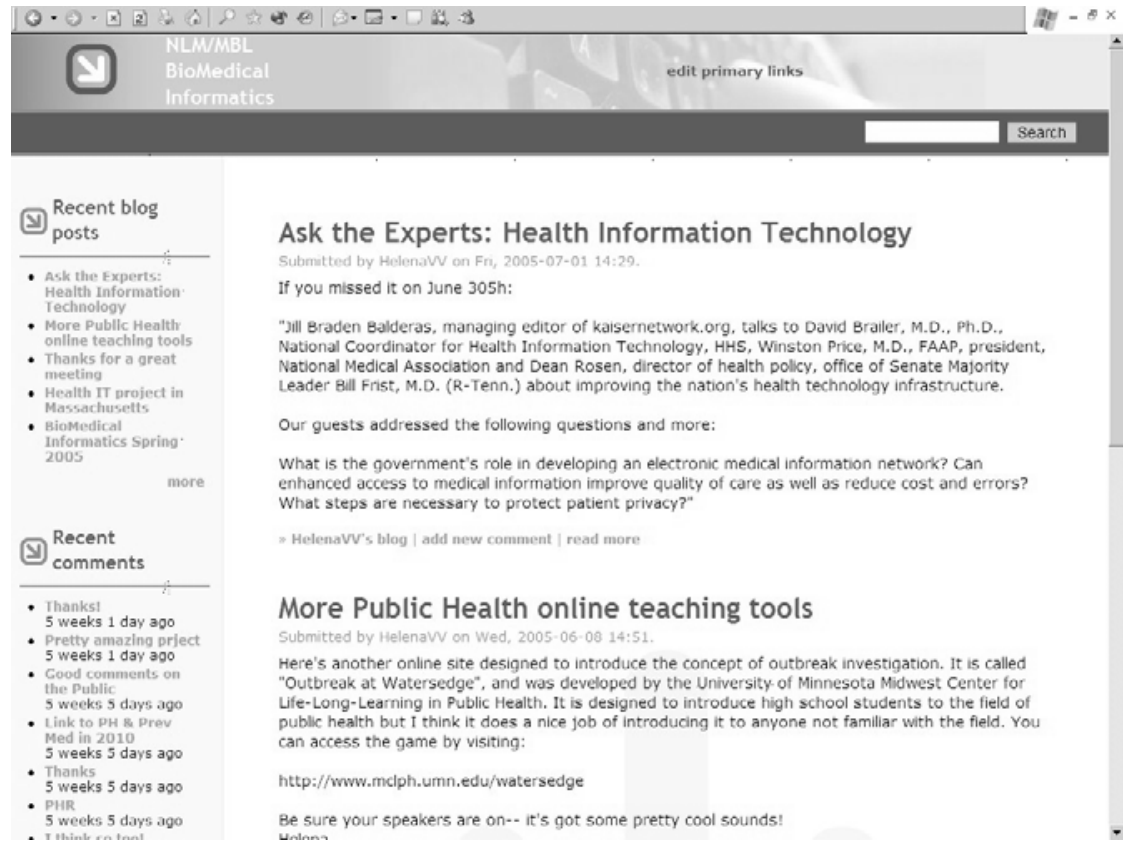

would influence the field of medical librarianship. These discussions were common both in class and in informal discussions held in non-class time. Those people who were not librarians were predominantly clinicians; this allowed exchanges that included the clinical view of informatics. With the overlap of medical librarians and clinicians, it was natural that a great deal of the discussion centered on the hospital setting and how the lecture topics and lessons could be practically applied.

One of the more obvious topics of interest to both the clinicians and hospital librarians concerned clinical information systems (CIS). A CIS is generally a large-scale, integrated computer system whose purpose is to coordinate and manage clinical practices across a department, hospital, or health care system. The presenter for the spring 2005 session on this topic was a distinguished professor from Duke University with a long history of accomplishment in the fields of Medical Informatics and Biomedical Engineering. The engaging lecture was a testament to the ability of the presenter as well as the fascinating nature of the topic. He instructed the class on CIS systems, explaining everything from background on why they are needed, to challenges and pitfalls on their 
implementation, to future directions and opportunities for continuing research. The subject was allotted two 90-minute class sessions, further evidence of the importance of the subject in medical informatics as well as to the faculty.

Even those sessions that would not seem at first glance to be of particular importance to hospital librarians contained aspects that can be applied to medical librarianship. One example of this was the Telemedicine session. Telemedicine involves cutting edge technology that allows the practice of medicine from a distance. It facilitates the interaction of doctor and patient from great distances, making it seem as if they are in the same room. Although it may appear at first that there is little place for a hospital librarian in relation to the technology involved, upon a closer look it can be related to the same processes that are offered to the in-house practice of medicine. Both the doctor and patient will need to be supported just as if they were on site. This could include doing searches for the clinician as well as finding and delivering educational material to the patient. Knowing that this technology is in the works will allow hospital librarians to plan for the future, as the practice of librarianship must evolve to meet the changing landscape of medicine.

There was a 90-minute session on PubMed and the NLM gateway. This, of course, only afforded time for a limited overview of the features of the databases. It was refreshing for the librarians to go to the head of the class for that session, which was not presented the same way as update sessions are presented for searchers. It was informative to witness a presentation of this resource to a class mixed with non-librarians. That, too, was an illustrative aspect of this session. Even the best searchers can usually learn a few tidbits from any of the NLM database presentations, and this session was well timed. The presentation came just a few days after several PubMed innovations had been implemented, which was a boon to quite a few of the expert searchers in the room. After this session, several of the librarians found themselves answering the questions of their non-librarian classmates. This enhanced the atmosphere of collegiality and emphasized again that the librarian is a valuable member of the health care team and involved in the mainstream of biomedical informatics.

The presenter for the Visible Human project was a person who was involved in the project from start to finish, and his observations and anecdotes related to the project were peerless. He described the physical challenges, the ethical considerations, and the changing technological hurdles. He shared how the project is being managed today, and showed examples of how the data is being used. After his presentation, librarians and clinicians alike could speak with understanding about the project and what it aimed to accomplish. 
Similar in spirit to that presentation was the session entitled, "The Internet: Reflections on What's Coming." It was a sort of showcase in the same way that the International Auto Show is for cars, with a brief overview of the beginnings of the Internet, leading up to how we got to where we are today, where we may be headed in the future, and a glimpse of a few "concept cars." After these presentations, the students in the course had the basic knowledge to connect these resources to teachers, learners, researchers, and administrators who could exploit them.

In one of the evening sessions, the fellows were taught to make Web pages using photographs taken of them during the opening reception, templates of information sheets, and Woods Hole photographs. Participants who already possessed these skills were able to help their classmates; participants who had never written Web pages were enthusiastic about the process. This session received some of the highest marks on the evaluations. The pages were available to all the fellows and provided the extra advantage of being used as a directory of names, faces, and backgrounds among the participants.

After a week filled with a crash course on the many ways in which technology is shaping the future of health care both in this country and around the world, it was vital that the faculty ground the students in the human side of these potential changes. On the last day, there was a session entitled, "Managing Technological Change." The instructor brought a wealth of real world examples of what has happened within organizations when implementing some of the possible systems and opportunities that had been discussed throughout the week. With her leadership, the class discussed reasons that situations had occurred as they did and ways that implementation could have been improved or problems could have been prevented. The instructor's interactive presentation was appealing and an excellent method for reminding the class of the human side that is involved in any technological adjustment.

All fellows were assigned to teams, and each team presented an assigned project at the end of the week. The goal was to incorporate what had been learned during the week into a presentation. The teams were arbitrarily (and appropriately for the location) named the Squids, the Lobsters, and the Sharks. This allowed the participants to get to know each other further by working together, as well as giving practical experience in working in teams and giving participants an assignment which required them to process the knowledge that they had acquired. The nomenclature also encouraged a spirit of fun and creativity. As work on each project progressed, team members divided the group responsibilities and e-mailed their work to each other, combining their contributions into single PowerPoint presentations, some of which included sound, video, and graphics. The Sharks presented Diagnostic Literature Information Portal: Gateway to Evidence-Based Diagnosis, then the Squids presented 
Structured Queries Using Intelligent Data Systems (S.Q.U.I.D.S.). Finally, the Lobsters presented The Born Identity (implanting RFID).

\section{EVALUATION}

In spite of the fact that some class days were extremely long, few participants had trouble maintaining their attention. The program was as interesting as it was well rounded. The course director continues to modify and enhance the program based on previous classes, suggestions, and new ideas from instructors and students alike. There is an evaluation component for each session; however, there is no evaluation for the course as a whole. Although the week is packed with relevant information, a librarian might suggest sessions on a few additional topics, although anyone would be hard pressed to figure out where to put any more sessions. The personal digital assistant (PDA) was an example of a topic noticeably missing, and it is of course a very useful tool in the biomedical informatics arsenal.

Electronic publishing was another topic not included, at a time when many librarians are grappling with the issues and trying to explain to busy clinicians why they cannot access everything online. Copyright is another issue that librarians face every day, and with which clinicians need at least a speaking acquaintance. It was not addressed as a session or mentioned in another session.

The week also included a great deal of fun, with social activities such as a lobster bake, a party hosted by the program director, and one free afternoon, which many participants spent taking a ferry trip together to Martha's Vineyard (see the Appendix). Participants were accommodated at MBL's dormitory and had time to socialize at the cafeteria there as well as at food-and-drink establishments on Water Street in Woods Hole, all of which were within a few blocks.

The authors highly recommend this course to any health care professional who wants to learn more about biomedical informatics. Fellows will meet and interact with instructors who are leaders and pioneers in their fields and who can help answer biomedical informatics questions. As one participant said, "I have been raving about the program to anyone who will listen . . . wishing I could go back for some more." Another quote: "It was a privilege to be a participant in the BioMedical Informatics Course at the Marine Biological Laboratory in Woods Hole, Mass. The Bioinformatics topics covered in the full schedule of lectures were exciting, timely, and best of all presented by the most knowledgeable professionals in the field. The students were an eclectic group of highly educated, motivated, and fun loving individuals. The camaraderie with the lecturers and students, the delicious sea food, and the surround- 
ing oceanic coast resulted in the most remarkable professional event that I have ever experienced."

To view an overview of the course and access an application for Woods Hole visit: <http://courses.mbl.edu/mi/>

To view an outline of the Woods Hole course: $<$ http://courses.mbl.edu/mi/outline.html >

For information on the Visible Human Project, go to: $<$ http://www.nlm.nih.gov/research/visible/visible_human.html>

\section{REFERENCES}

1. Patel, Vimla L.; Branch, Timothy; Cimino, Andria; Norton, Cathy; and Cimino, James J. "Participant Perceptions of the Influences of the NLM-Sponsored Woods Hole Medical Informatics Course." Journal of the American Medical Informatics Association 12, no. 3 (2005): 256-62.

2. Greenes, Robert A., and Shortliffe, Edward H. "Medical Informatics: An Emerging Academic Discipline and Institutional Priority." Journal of the American Medical Association 263, no. 8 (1990): 1114-20.

3. King, Samuel Bishop, and MacDonald, Kate. "Metropolis Redux: The Unique Importance of Library Skills in Informatics." Journal of the Medical Library Association 92(April 2004): 209-17.

\section{APPENDIX}

Photos from Woods Hole and Martha's Vineyard



[Insert Image: Eel pond with Swope dormitory in the Distance (building on right)] 
APPENDIX (continued)



[Insert image: Tour of the Marine Biological Laboratory-Viewing a squid (loligo)]

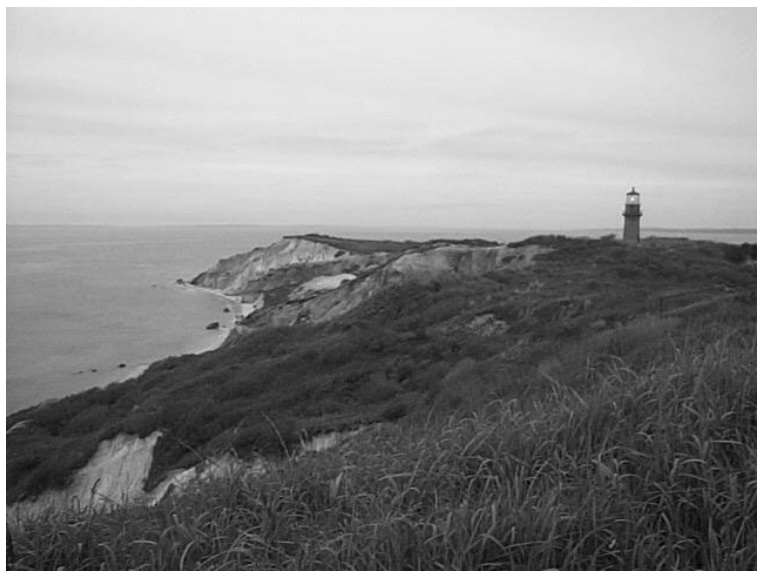

[insert image: Gays Head lighthouse and cliff on Martha's Vineyard] 